\title{
Endoscopic resection of early gastric cancer
}

\author{
TAKuji Gotoda \\ National Cancer Center Hospital, 5-1-1 Tsukiji, Chuo-ku, Tokyo 104-0045, Japan
}

\begin{abstract}
The purpose of this review is to examine recent advances in the techniques and technologies of endoscopic resection of early gastric cancer (EGC). Endoscopic mucosal resection (EMR) of EGC, with negligible risk of lymph node metastasis, is a standard technique in Japan and is increasingly becoming accepted and regularly used in Western countries. EMR is a minimally invasive technique which is safe, convenient, and efficacious; however, it is insufficient when treating larger lesions. The evidence suggests that difficulties with the correct assessment of depth of tumor invasion lead to an increase in local recurrence with standard EMR when lesions are larger than $15 \mathrm{~mm}$. A major factor contributing to this increase in local recurrence relates to lesions being excised piecemeal due to the technical limitations of standard EMR. A new development in endoscopic techniques is to dissect directly along the submucosal layer - a procedure called endoscopic submucosal dissection (ESD). This allows the en-bloc resection of larger lesions. ESD is not necessarily limited by lesion size and it is predicted to replace conventional surgery in dealing with certain stages of ECG. However, it still has a higher complication rate when compared to standard EMR, and it requires high levels of endoscopic skill and experience. Endoscopic techniques, indications, pathological assessment, and methods of endoscopic resection of EGC need to be established for carrying out appropriate treatment and for the collation of long-term outcome data.
\end{abstract}

Key words Early gastric cancer - Endoscopic mucosal resection (EMR) - Endoscopic submucosal dissection (ESD) · Complications $\cdot$ Histological staging

\section{Introduction}

In the management of early gastric cancer (EGC) (see Fig. 1), a major role is played by therapeutic endoscopy. Its indications can be broadly divided into four

Offprint requests to: $\mathrm{T}$. Gotoda

Received: July 21, 2006 / Accepted: November 14, 2006 categories: (1) excision or fulguration, (2) palliative recanalization of luminal obstruction, (3) hemorrhage control, and (4) others. Endoscopic excision of cancer, using a high-frequency electric current (HFEC), or fulguration, using laser irradiation, microwave coagulation, or local injection of anticancer agents has been used with the intention to cure. Re-canalization of luminal obstruction can be achieved using endoscopic laser irradiation, microwave coagulation, bougienage, or stent placement. Endoscopic injection of pure alcohol or hypertonic saline with diluted epinephrine, the application of heater probe, argon plasma, or microwave coagulation, and HFEC or laser irradiation have been used to arrest bleeding from cancer, with varying degrees of success.

The role of endoscopic surgery in the management of EGC will be the focus of this review.

Endoscopic treatment for EGC is currently standard practice in Japan; outside Japan, it is increasingly gaining acceptance worldwide [1,2]. Endoscopic resection is comparable in many respects to conventional surgery, with the advantages of being less invasive and more economical. The extremely low incidence of lymph involvement in certain stages of EGC means that cure can be accomplished by such local treatment in selected cases. Endoscopic resection allows complete pathological staging of the cancer, which is critical, as this allows stratification and refinement of further treatment [3]. Patients who are identified to have no risk or a low risk of developing lymph node metastasis, relative to the perioperative risks associated with surgery, are ideal candidates for endoscopic resection [4]. Other endoscopic techniques may also cure EGC by fulgurating it, but they do not provide any pathological specimen [5]. Without a specimen, tumor stage cannot be assessed. Thus, the patient's prognosis cannot be estimated and potential needs for additional therapy, which may be curative, cannot be assessed $[6,7]$. 


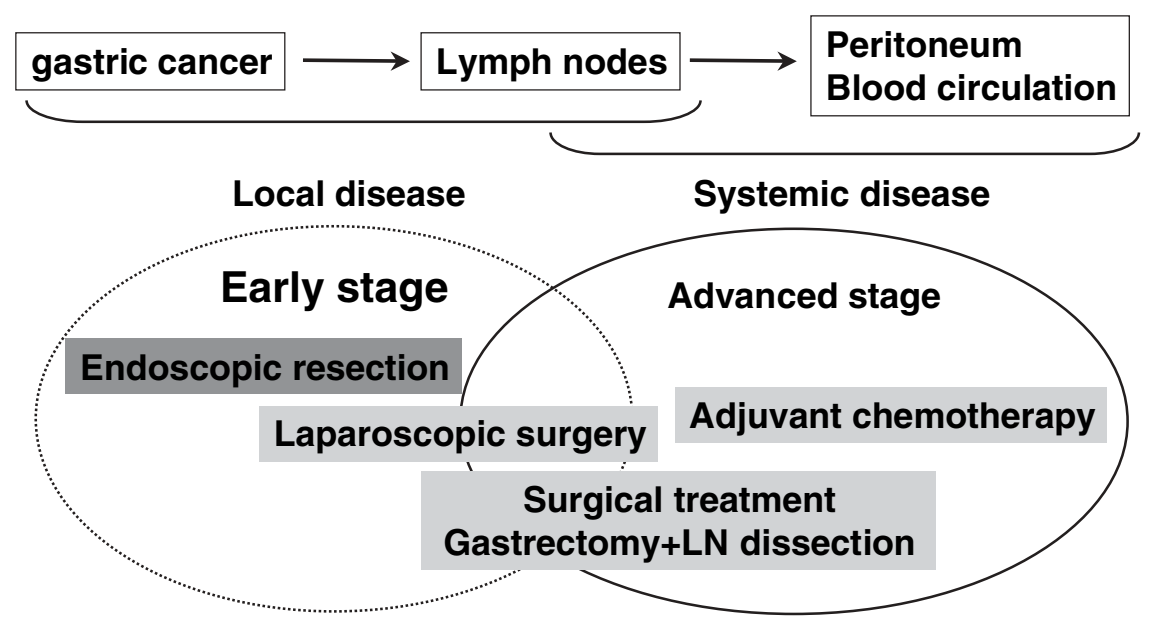

Fig. 1. Treatment strategy for gastric cancer. $L N$, lymph node
Recent advances, including the categorizing of endoscopic resection as standard endoscopic mucosal resection (EMR) or endoscopic submucosal dissection (ESD) will be described.

\section{Principle of endoscopic resection}

EGC is defined as GC in which tumor invasion is confined to the mucosa or submucosa (T1 cancer), irrespective of lymph node status [8], considering the adverse impact of lymph node metastasis on a patient's prognosis $[9,10]$. Gastrectomy with lymph node dissection had been the gold standard treatment here in Japan for all patients with operable gastric cancer, including EGC [11-13]. This policy of radical surgery for all such cases carries significant risks of morbidity and mortality and is associated with a long-term reduction in patients' quality of life [14,15].

Analyses of databases containing hundreds of thousands of pathology reports, patients' histories, and longterm survival data from the National Cancer Center Hospital and other units in Japan have demonstrated that the 5-year cancer-specific survival rates of EGC limited to the mucosa or the submucosa are $99 \%$ and $96 \%$, respectively [16]. In patients with cancer limited to the mucosa, the incidence of lymph node metastasis is less than $3 \%$. By comparison, this risk increases to around $20 \%$ when the cancer invades the submucosa [17]. With stratification, subgroups of patients with EGC who have practically no risk of lymph node metastasis have been identified [18]. Patients with EGC who meet these very specific endoscopic and pathological criteria are ideal candidates to have their cancer excised through the endoscope. Patients who have lesions suspected to contain EGC are also ideal candidates to undergo endoscopic resection.

The major advantage of endoscopic resection is its ability to provide pathological staging without preclud- ing future surgical therapy $[19,20]$. After endoscopic resection, pathological assessment of depth of cancer invasion, degree of differentiation of the cancer, and extent of lymphovascular invasion allows the risk of lymph node metastasis to be predicted, using published data of patients with similar findings [21]. The risk of developing lymph node metastasis or distant metastasis is then weighed against the risk of surgery [22]. Such precise staging, unfortunately, cannot be achieved as accurately with any imaging technique currently available [23]. For example, while endoscopic ultrasound (EUS) is accurate for tumor depth staging, this is only possible in $80 \%$ to $90 \%$ of cases [24]. Hence, any treatment plan based on EUS recommendations potentially means that, in $10 \%$ to $20 \%$ of cases, patients may be subjected to unnecessary surgery [25-27]. The final staging can only be done through formal histological analysis, which endoscopic excision can achieve [28,29].

\section{Indications for endoscopic resection}

Currently accepted indications for endoscopic resection of EGC include the resection of small intramucosal EGCs of intestinal histology type (Fig. 2) [30]. The rationale for this recommendation is based upon the knowledge that larger-size lesions or lesions with diffuse histology type are more likely to extend into the submucosal layer and thus have a higher risk of lymph node metastasis. In addition, resection of large lesion has not been technically feasible until the development of ESD techniques. Therefore, at present, the accepted indications for EMR are: (1) well-differentiated elevated cancers less than $2 \mathrm{~cm}$ in diameter and (2) small $(\leqq 1 \mathrm{~cm})$ depressed lesions without ulceration. Also, these lesions must be moderately or well-differentiated cancers confined to the mucosa and have no lymphatic or vascular involvement [31]. 


\begin{tabular}{|c|c|c|c|c|c|c|}
\hline \multirow{3}{*}{ Depth } & \multicolumn{4}{|c|}{ Mucosal cancer } & \multicolumn{2}{|c|}{ Submucosal cancer } \\
\hline & \multicolumn{2}{|c|}{ UL(-) } & \multicolumn{2}{|c|}{ UL(+) } & \multirow{2}{*}{$\begin{array}{l}\text { SM1 } \\
\leqq 30\end{array}$} & \multirow{2}{*}{$\begin{array}{c}\text { SM2 } \\
\text { any size }\end{array}$} \\
\hline & $\leqq \mathbf{2 0}$ & $20<$ & $\leqq 30$ & $30<$ & & \\
\hline \multicolumn{7}{|l|}{ Differentiated } \\
\hline Undifferentiated & & & & & & \\
\hline
\end{tabular}

Guideline criteria for EMR Surgery

\begin{tabular}{|c|c|c|c|c|c|c|}
\hline \multirow{3}{*}{ Depth } & \multicolumn{4}{|c|}{ Mucosal cancer } & \multicolumn{2}{|c|}{ Submucosal cancer } \\
\hline & \multicolumn{2}{|c|}{ UL(-) } & \multicolumn{2}{|c|}{ UL(+) } & \multirow{2}{*}{$\begin{array}{l}\text { SM1 } \\
\leqq 30\end{array}$} & \multirow{2}{*}{$\begin{array}{c}\text { SM2 } \\
\text { any size }\end{array}$} \\
\hline & $\leqq \mathbf{2 0}$ & $20<$ & $\leqq 30$ & $30<$ & & \\
\hline Differentiated & & & & & & \\
\hline Undifferentiated & & & & & & \\
\hline
\end{tabular}

Guideline criteria for EMR

Extended criteria for ESD
Surgery

Consider surgery*
Fig. 2. Guideline criteria for endoscopic resection in the endoscopic mucosal resection $(E M R)$ era. Size is shown in $\mathrm{mm}$. $U L$, ulcerative findings; $S M$, submucosal invasion
Fig. 3. Proposed extended criteria for endoscopic resection in the endoscopic submucosal dissection (ESD) era. Asterisk; although the possibility of metastasis is very low in this category, surgery is considered because endoscopic en-bloc removal is sometimes difficult in undifferentiated-type tumors

Table 1. Early gastric cancer with no risk of lymph node metastasis

\begin{tabular}{llc}
\hline Criteria & Incidence & $95 \% \mathrm{CI}$ \\
\hline $\begin{array}{l}\text { Intramucosal cancer } \\
\text { Differentiated adenocarcinoma }\end{array}$ & $0 / 1230 ; 0 \%$ & $0-0.3 \%$ \\
$\begin{array}{l}\text { No lymphovascular invasion } \\
\text { Irrespective of ulcer findings } \\
\text { Tumor less than } 3 \mathrm{~cm} \text { in size }\end{array}$ & & \\
\hline $\begin{array}{l}\text { Intramucosal cancer } \\
\text { Differentiated adenocarcinoma }\end{array}$ & $0 / 929 ; 0 \%$ & $0-0.4 \%$ \\
No lymphovascular invasion & & \\
$\begin{array}{l}\text { Without ulcer findings } \\
\text { Irrespective of tumor size }\end{array}$ & & $0-2.6 \%$ \\
\hline $\begin{array}{l}\text { Undifferentiated intramucosal cancer } \\
\text { No lymphovascular invasion }\end{array}$ & $0 / 141 ; 0 \%$ & \\
Without ulcer findings & & \\
Tumor less than 2 cm in size & & $0-2.5 \%$ \\
\hline $\begin{array}{l}\text { Minute submucosal penetration (SM 1) } \\
\text { Differentiated adenocarcinoma } \\
\text { No lymphovascular invasion } \\
\text { Tumor less than } 3 \text { cm in size }\end{array}$ & $0 / 145 ; 0 \%$ & \\
\hline
\end{tabular}

Clinical observations have noted, however, that the accepted indications for ER can be too strict and can lead to unnecessary surgery [32]. Therefore, extended criteria for ER have been proposed. The upper limit of the $95 \%$ confidence interval (CI) calculated from these early studies, however, was too broad for clinical use because of their small sample size [33-37]. More recently, however, using a large database involving more than 5000 patients who underwent gastrectomy with meticulous R2 level lymph node dissection, Gotoda and 


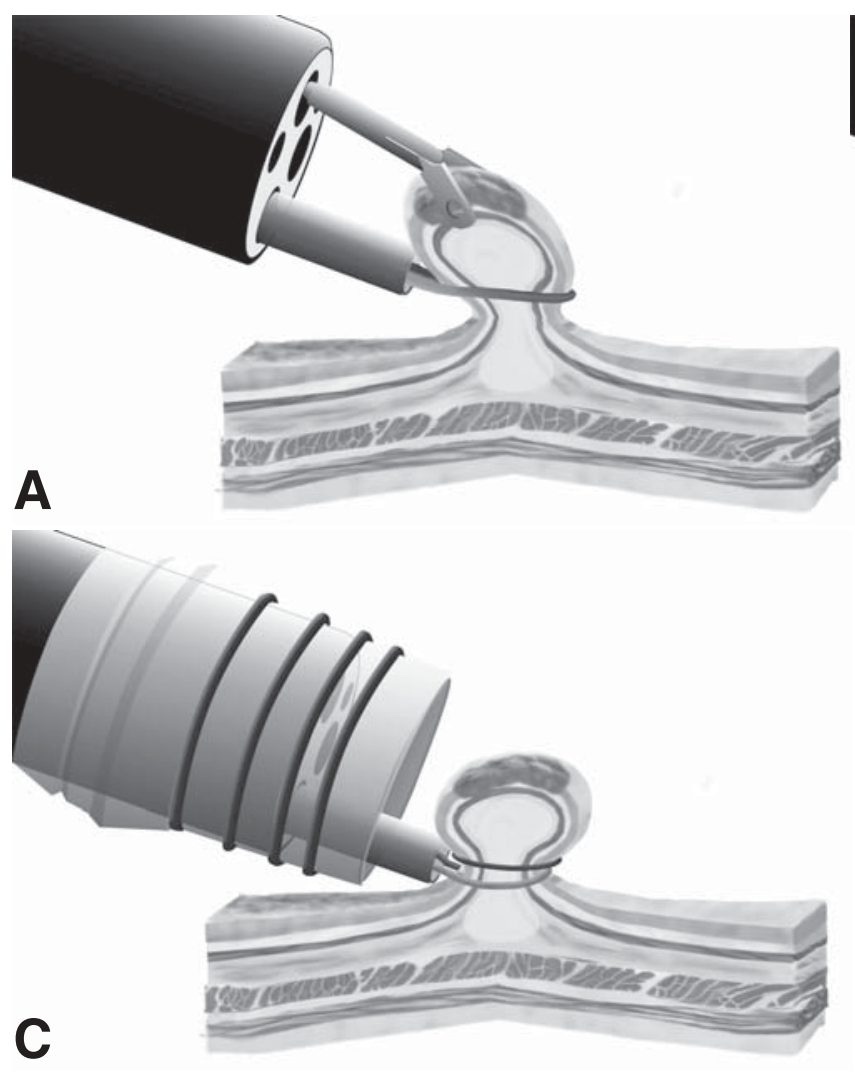

colleagues [38] were able to define further the risk of lymph node metastasis in additional groups of patients with EGC with increased certainty (Table 1). These groups of patients were shown to have no or lower risks of lymph node metastasis than the risks of mortality from surgery. The results of this study have allowed the development of an expanded list of candidates suitable for endoscopic resection (Fig. 3) [39].

\section{Endoscopic resection for cure in EGC}

Learning from the successful application of polypectomy used to remove early colon cancer [40], endoscopic polypectomy to treat pedunculated or semipedunculated EGC was first described in Japan in 1974. By 1984, an EMR technique called the "strip biopsy" (Fig. 4A) was first described as an extension of endoscopic snare polypectomy [41]. In this method, a double-channel endoscope is used. After submucosal injection of saline under the lesion, the lesion is lifted using a grasper, while a snare, inserted through the second working channel, is used to remove the lesion. In 1988, another technique, EMR with the local injection of hypertonic saline/diluted epinephrine solution was described [42]. In this technique, after the injection of hypertonic saline and diluted epinephrine, the periphery of the lesion is

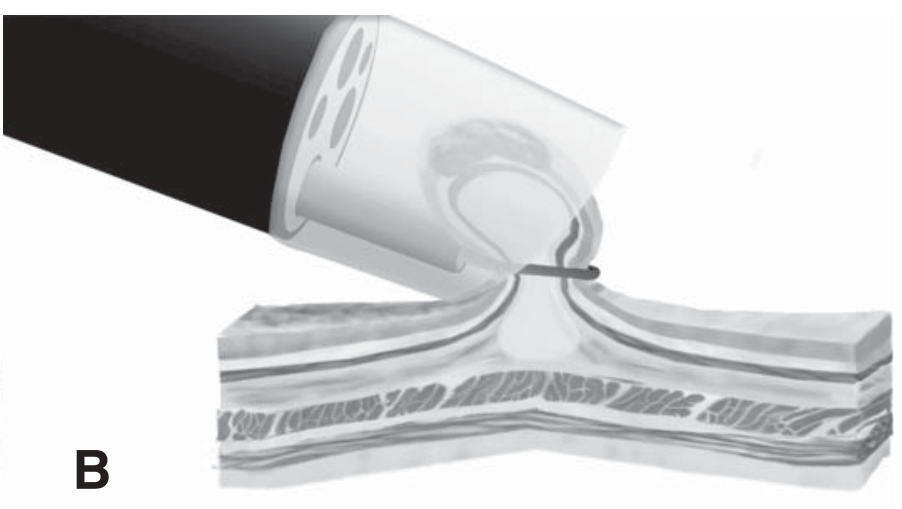

Fig. 4A-C. Standard EMR methods. A Strip biopsy; B cap-fitted panendoscope (EMR-C); C EMR with ligation (EMR-L)

cut using a needle knife. The lesion is then removed using a snare. EMR allowed increased precision to be applied, thus permitting the entire lesion to be removed en bloc. However, the technique also requires considerable skills, and the use of the needle knife has higher risks for perforation.

A method of EMR with a cap-fitted panendoscope (EMR-C), developed in 1992 for the resection of early esophageal cancer, was directly applicable for the resection of EGC (Fig. 4B) [43]. The technique utilizes a clear plastic cap that is connected to the tip of a standard endoscope. Different sized caps are available according to the diameter of the endoscope and the size of the target lesions [44] (Fig. 5). After the submucosal injection of the lesion, a specialized crescent-shaped snare is deployed in the groove at the tip of the cap. The lesion is then sucked into the cap while the snare is closed. Thus, resection can be safely performed through the submucosal layer under the lesion [45].

The technique of EMR with ligation (EMR-L; Fig. 4C) uses a standard endoscopic variceal ligation device to capture the lesion and make it into a polypoid lesion by deploying the band underneath it [46]. The lesion above or below the band is then excised. EMR-C and EMR-L have the advantage of being relatively simple, with the use of a standard endoscope and no requirement for an additional assistant. These techniques how- 

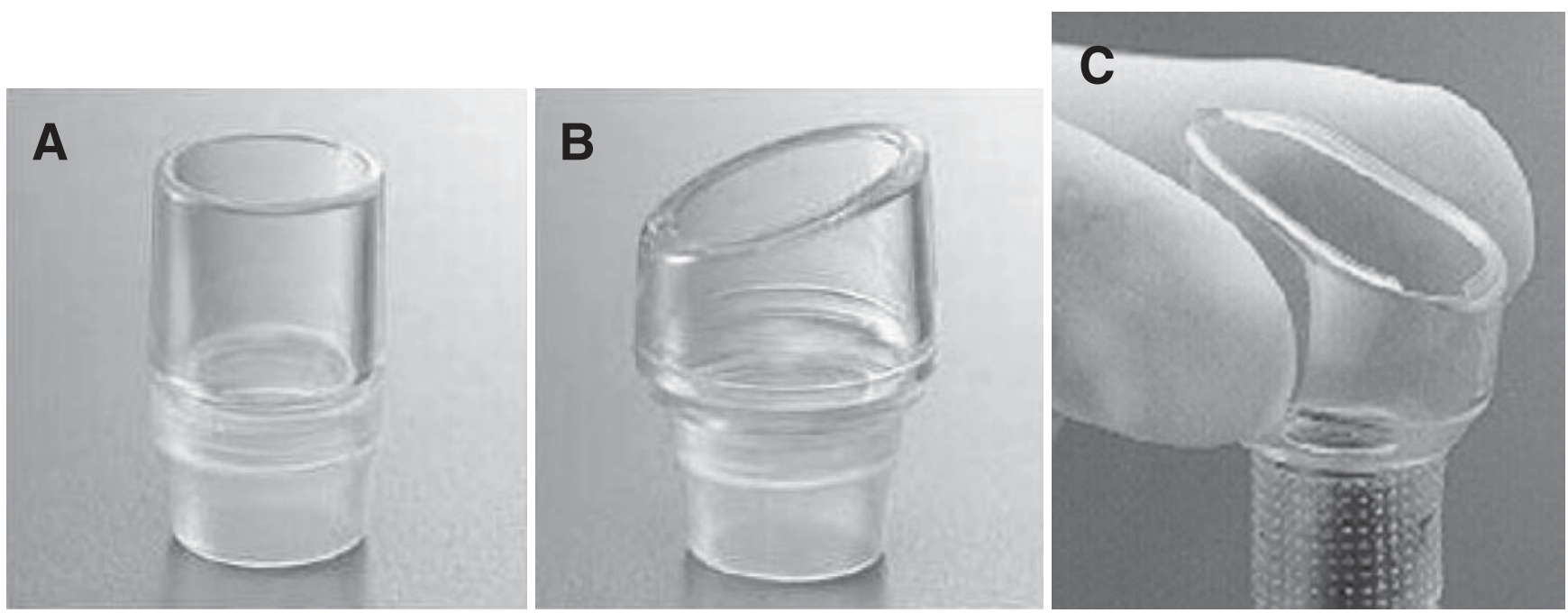

Fig. 5A-C. Several sizes and types of caps for achieving an EMR-C procedure. A Straight hard type (MH-462-466/483/MAJ663; Olympus, Tokyo, Japan); B wide opening oblique with rim (hard type; MAJ-295-297; Olympus, Tokyo, Japan); C wide opening oblique with rim (soft type; D-206-01-06; Olympus, Tokyo, Japan)

Table 2. Recurrence rates after conventional EMR for early gastric cancer

\begin{tabular}{llr}
\hline Author & \multicolumn{1}{c}{ Methods } & Recurrence rate \\
\hline Tanabe et al. & Strip biopsy, EAM & $3.5 \%(15 / 423)$ \\
Kawaguchi et al. & Strip biopsy, EMR-C & $36.5 \%(97 / 266)$ \\
Ida et al. & EMR + Laser & $6.7 \%(11 / 165)$ \\
Chonan et al. & EMR & $10.9 \%(21 / 193)$ \\
Hirao et al. & ERHSE & $2.3 \%(8 / 349)$ \\
Mitsunaga et al. & Strip biopsy & $18.2 \%(54 / 296)$ \\
NCCH (1978-1998) & Strip biopsy, EMR + laser & $8.5 \%(53 / 620)$ \\
\hline
\end{tabular}

EAM, Endoscopic aspiration mucosectomy; EMR-C, EMR with cap; ERHSE, EMR with local injection of hypertonic saline-epinephrine

ever, cannot be used to resect lesions larger than $15 \mathrm{~mm}$ in one piece $[47,48]$. Specimens obtained following piecemeal resections are difficult for the pathologist to analyze, and they render pathological staging inadequate. This is a major factor leading to the high risk of recurrence when these techniques are used (Table 2) [49]. In attempt to overcome this problem, a method of en-bloc resection was developed [50].

Endoscopic techniques that involve direct dissection of the submucosa using modified needle knives have recently been classified as ESD techniques [51]. ESD using an insulation-tipped diathermy knife (IT knife), was first developed at the National Cancer Center Hospital $[52,53]$. ESD using the IT knife is perhaps the most commonly performed ESD today in Japan (Fig. 6) [54]. ESD is reputed to be superior to other endoscopic methods in the treatment of EGC, and it provides enbloc specimens with a standard single-channel gastroscope. This novel and promising procedure has the advantage of achieving large en-bloc resections (Fig. 7); also, it allows precise histological staging and may prevent disease recurrence. Other devices used for ESD have also been described, such as the hook knife [55], flex knife [56], and a knife in a small-caliber-tip transparent hood [57]. Despite requiring significant additional technical skills and a longer procedure time $[58,59]$, these ESD techniques are rapidly gaining popularity in Japan, primarily because of their ability to remove large EGCs en bloc [60].

\section{Complications of endoscopic resections}

The complications of endoscopic resection for EGC include pain, bleeding, and perforation. Pain after resection is typically mild [61]. Standard doses of proton-pump inhibitors twice a day are prescribed for 8 weeks, and patients are typically fasted for $24 \mathrm{~h}$ after the procedure [62], followed by clear liquid on the second day, and a soft diet on day 3 . Bleeding is the most common 

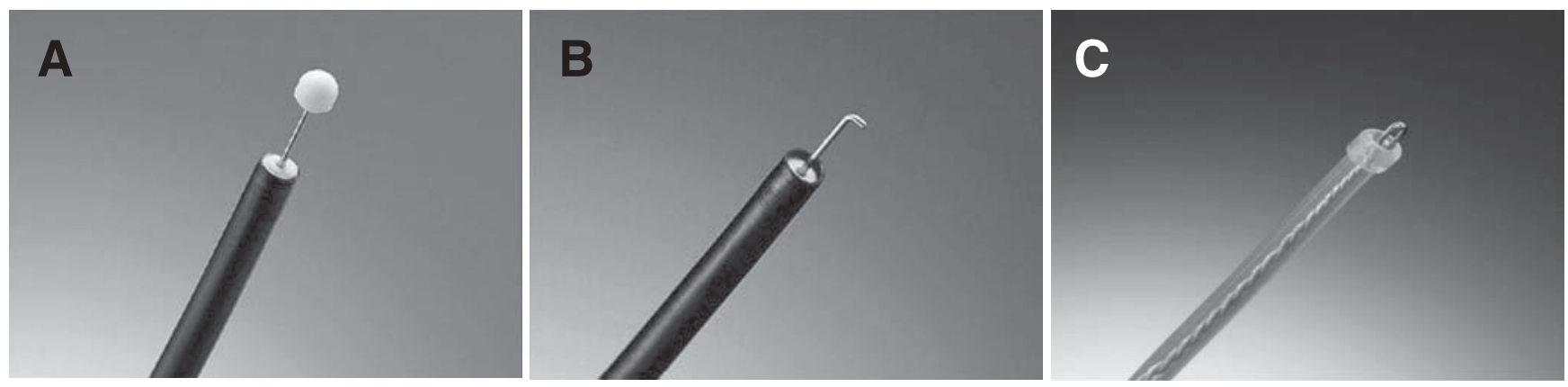

Fig. 6A-C. Different types of endoscopic equipment for ESD. A Insulation-tipped diathermic electrosurgical knife (IT knife); B hook knife; $\mathbf{C}$ flex knife
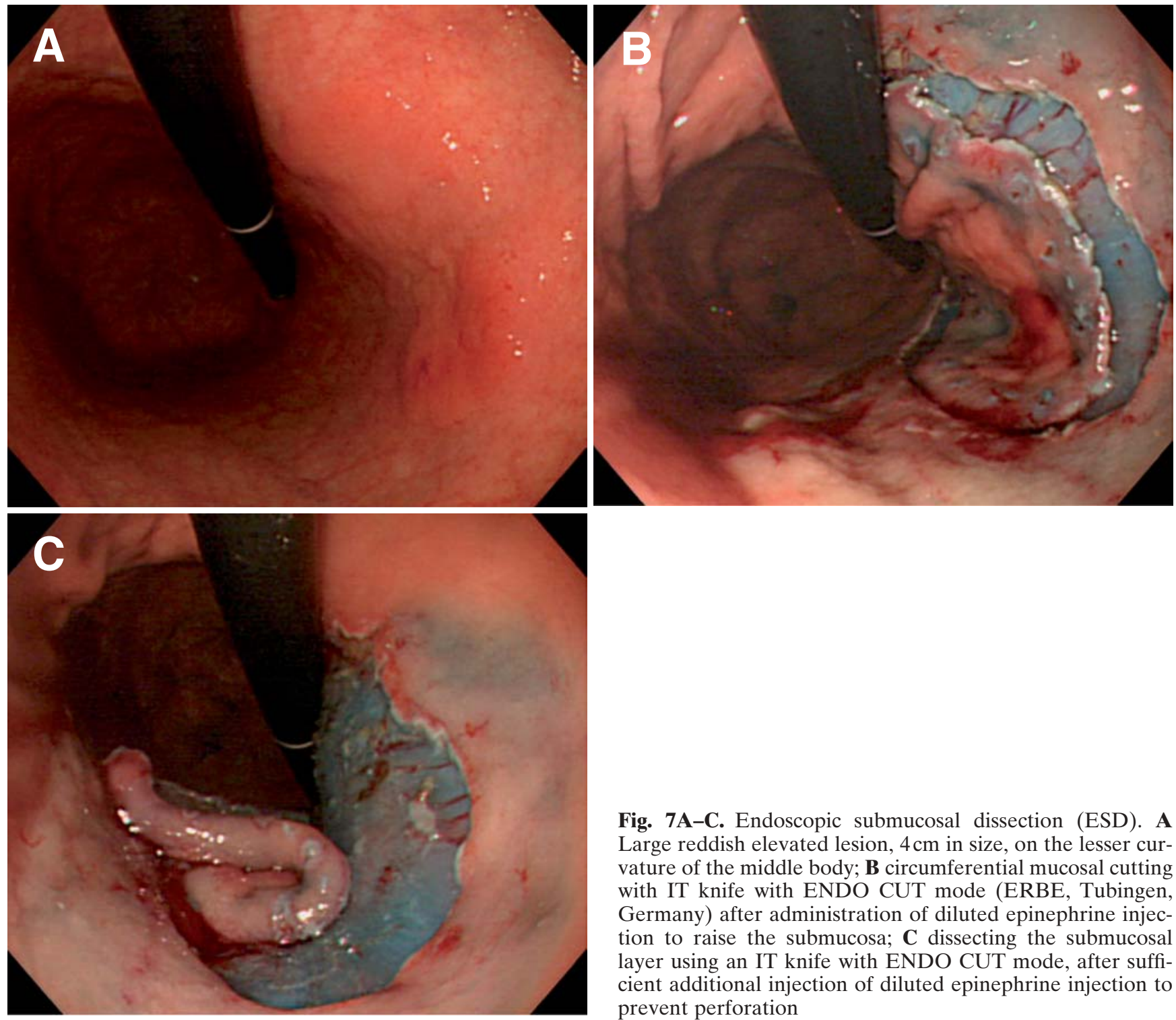

Fig. 7A-C. Endoscopic submucosal dissection (ESD). A Large reddish elevated lesion, $4 \mathrm{~cm}$ in size, on the lesser curvature of the middle body; $\mathbf{B}$ circumferential mucosal cutting with IT knife with ENDO CUT mode (ERBE, Tubingen, Germany) after administration of diluted epinephrine injection to raise the submucosa; $\mathbf{C}$ dissecting the submucosal layer using an IT knife with ENDO CUT mode, after sufficient additional injection of diluted epinephrine injection to prevent perforation 
complication, occurring in up to $8 \%$ of patients undergoing standard EMR and in up to $7 \%$ of patients undergoing ESD $[63,64]$ (Table 3).

Immediate bleeding appears more common with resections of tumors located in the upper third of the stomach. During ESD, immediate minor bleeding is not uncommon, but it can be successfully treated by grasping and coagulation of the bleeding vessels, using hot biopsy forceps (Fig. 8A,B) (Boston, MA, USA) with 80-W soft-mode coagulation (ICC 200; Erbe, Germany) or bipolar hemostatic forceps (Pentax., Tokyo, Japan) designed to reduce a deeper coagulation effect (30-W

Table 3. Relationships between delayed bleeding and tumor location, size, and ulcer findings

\begin{tabular}{llcr}
\hline & & Delayed bleeding & $P$ value \\
\hline Location & $\mathrm{U}$ & $1 \%(1 / 176)$ & \\
& $\mathrm{M}$ & $6 \%(24 / 431)$ & 0.001 \\
\multirow{4}{*}{ Size $(\mathrm{mm})$} & $\mathrm{L}$ & $7 \%(31 / 426)$ & $<0.001$ \\
& $\leqq 20$ & $5 \%(35 / 719)$ & \\
& $21-30$ & $7 \%(13 / 176)$ & 0.184 \\
Ulcer finding & $\geqq 31$ & $8 \%(11 / 138)$ & 0.139 \\
& Positive & $5 \%(13 / 243)$ & \\
& Negative & $6 \%(46 / 790)$ & 0.781 \\
\hline
\end{tabular}

U, Upper third of stomach; M, middle third; L lower third bipolar mode with ICC 200 generator) [65]. Endoclips are often deployed for severe bleeding. Delayed bleeding, manifested as hematemesis or melena at 0 to 30 days after the procedure, is treated by emergency endoscopy performed after fluid resuscitation, using techniques similar to those described [66]. Delayed bleeding is common after ESD and is closely related to tumor location and size [67].

Perforation is uncommon during EMR, but is seen relatively more commonly during ESD. The risk of perforation during ESD is around 4\% (Table 4). These perforations are typically closed with the aid of endoclips, as previously described (Fig. 8C,D) [68,69], because the stomach in patients during gastric EMR or ESD is thought to be comparatively clean due to their fasting before undergoing these procedures, and because of the antibacterial effect of gastric acid.

Vital signs such as blood pressure, oxygen saturation, and electrocardiograms must be checked during endoscopic procedures. If pneumoperitoneum due to perforation (Fig. 8E) is severe, breathing deterioration or neurogenic shock can occur. To prevent these complications (so-called abdominal compartment syndrome), when gastric perforation occurs, decompression of the pneumoperitoneum must be performed with a $14-\mathrm{G}$ puncture needle with side slits under transabdominal
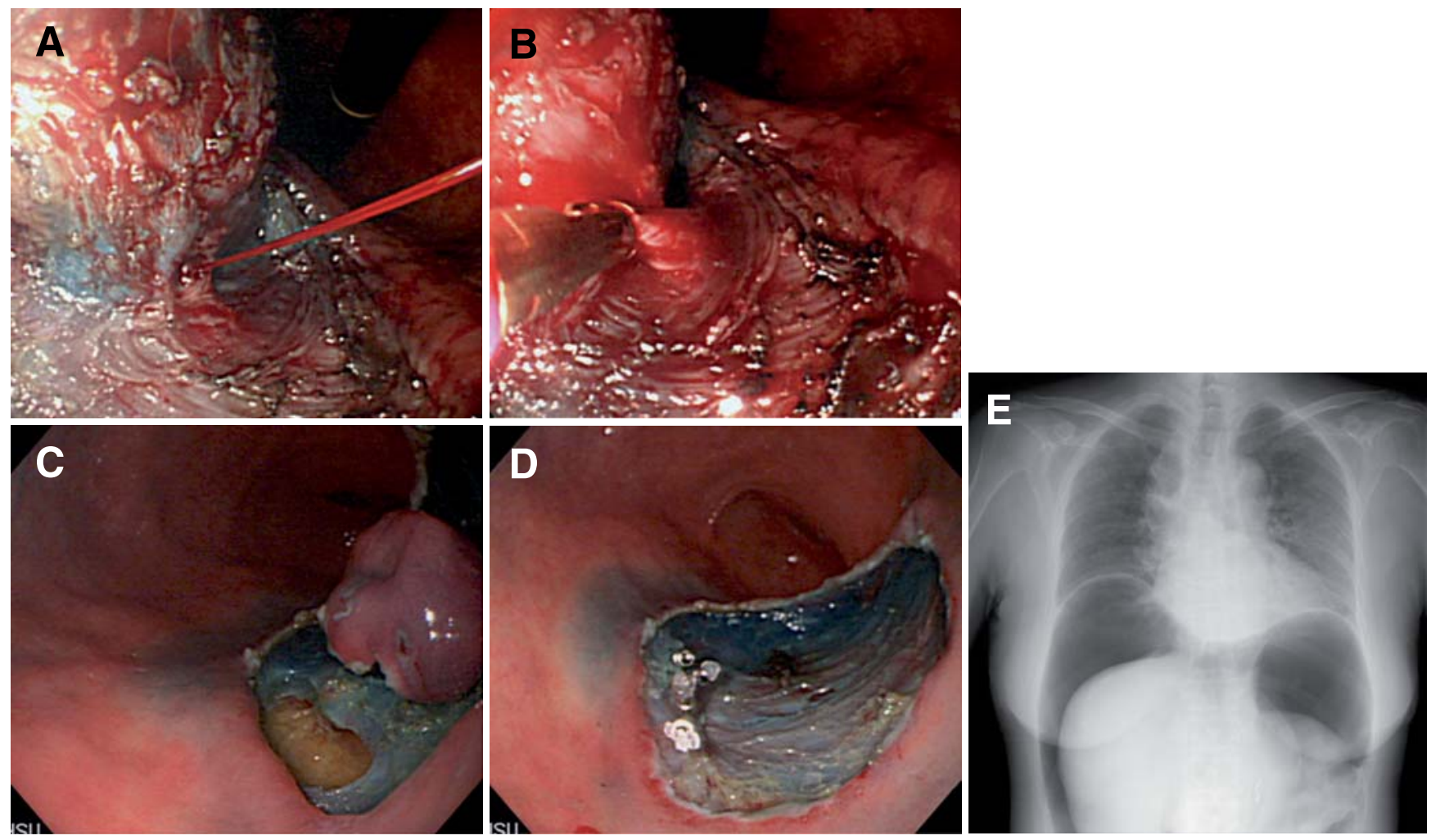

Fig. 8A-E. Management of complications during ESD. A Arterial bleeding from submucosal layer; B hemostasis with hot biopsy forceps with 80 -W soft-mode coagulation; $\mathbf{C}$ perforation caused by IT knife; $\mathbf{D}$ complete closure with endoscopic clips $\mathbf{E}$ pneumoperitoneum due to perforation 
Table 4. Relationships between risk of perforation and tumor location, size, and ulcer findings

\begin{tabular}{llcl}
\hline & & Risk of perforation & $P$ value \\
\hline Location & $\mathrm{U}$ & $7 \%(13 / 176)$ & $<0.001$ \\
& $\mathrm{M}$ & $4 \%(16 / 431)$ & $<0.05$ \\
\multirow{5}{*}{ Size $(\mathrm{mm})$} & $\mathrm{L}$ & $1 \%(6 / 426)$ & \\
& $\leqq 20$ & $3 \%(18 / 719)$ & \\
& $21-30$ & $3 \%(6 / 176)$ & 0.184 \\
Ulcer finding & $\geqq 31$ & $8 \%(11 / 138)$ & 0.139 \\
& Positive & $6 \%(14 / 243)$ & $<0.05$ \\
& Negative & $3 \%(21 / 790)$ & \\
\hline
\end{tabular}

U, Upper third of stomach; M, middle third; L, lower third

ultrasonographic guidance. Recently, in an attempt to minimize the chance of gastric perforation, polyethylene glycol or sodium hyaluronate has been used as the injection agent; this has been reported to help make ESD easier and safer, as these agents stay longer in the submucosa and produce clearer dissection planes $[70,71]$. Considering the tissue damage that can occur after injection of the solution during endoscopic resection, an efficient one should be used [72].

\section{Pathological assessment after endoscopic resection}

Endoscopic resection has generally been unpopular in the West, because of the very low incidence of suitable EGC cases. The diagnostic difficulties related to endoscopy seem to be a factor, but the low incidence of EGC may also be explained by the different histological criteria applied in the West and Japan; that is to say, most intestinal-type mucosal cancer in Japan is not regarded as a cancer in the West [73]. Whatever the case, such lesions ought to be diagnosed as neoplastic or dysplastic on histology, in line with the Vienna classification [74], and they should be subjected, where appropriate, to endoscopic resection.

The importance of meticulous pathological staging after endoscopic resection cannot be overemphasized. Accurate staging can only be achieved when the specimen is properly oriented by the endoscopist or their assistant immediately after excision in the endoscopy unit prior to the specimen being immersed in formaldehyde.

Orientation of the specimen is best performed by fixing its periphery with thin needles inserted into an underlying plate of rubber or wood. The submucosal side of the specimen is placed in contact with the plate. After fixation, the specimen is sectioned serially at $2-\mathrm{mm}$ intervals parallel to a line that includes the closest resection margin of the specimen, so that both lateral and vertical margins are assessed. The depth of tumor invasion $(\mathrm{T})$ is then evaluated, along with the degree of dif- ferentiation and lymphatic or vascular involvement, if any [75]. The report must include histological type, tumor depth, size, location, and macroscopic appearance. The presence of ulceration and lymphatic and/or venous involvement, and the status of the resection margins should be reported in detail to determine the curability.

\section{Outcomes of endoscopic resection}

The outcomes of EMR have been studied in detail. The successful outcomes observed from such studies have allowed EMR to become the standard treatment for EGC in Japan [76]. Kojima and colleagues [77] have reviewed the outcomes of EMR from 12 major institutions in Japan. The inject, lift, and cut, EMR-C, and EMR-L techniques were commonly used and they achieved en-bloc resection in about three-quarters of the patients in whom they were used. The diseasespecific survival rate was $99 \%$, although not all studies reported long-term outcomes. As previously mentioned, standard EMR techniques are associated with risks of recurrence, especially when resections are not performed en bloc, or when the resection margins are involved by tumor. The risk of local recurrence after EMR varies from $2 \%$ to $35 \%$. ESD is still investigational and demands an extremely high level of skill. In some specialized centers in Japan, the long-term outcomes of patients who have had endoscopic resection using the extended criteria are currently being studied [78]. The incidence of metachronous multiple gastric cancer in patients who have undergone endoscopic resection for the first lesion should be prospectively investigated to determine the interval of sufficient surveillant endoscopy $[79,80]$.

\section{Prospects for the future}

Endoscopic procedures for the excision of EGC need to be safe, effective, and applicable to a wide range of clinical situations. One is well aware that the rapid progress of technologies such as ESD has been responsible for advances in the endoscopic resection of EGC. Although several endoscopic devices have been developed solely to make ESD easier and safer, this technique still requires an experienced endoscopist with a high level of skill, because the procedure is performed through only one gastroscope, thus requiring one-handed surgery [81]. Recently, a procedure involving countertraction of lesions for gastric ESD has been described, but it is still under development. In brief, this process involves percutaneous traction-assisted EMR (PTAEMR) [82]. This invasive procedure is extremely 
complicated. We prefer a two-handed technique, as in conventional surgery, and are now planning a clinical trial using magnetic-assisted ESD [83]. In order to further extend the indications for treating EGC with less invasive surgery, endoscopic resection combined with laparoscopic regional lymph-node dissection should be considered $[84,85]$.

In conclusion, endoscopic resection of EGC is well established as a standard therapy in Japan and is increasingly becoming accepted and regularly used in other countries. The indications, pathological assessment, and techniques of endoscopic resection employed in the treatment of EGC are demanding. ESD, a modification of EMR, has been developed to allow the resection of larger lesions in an en-bloc manner; the early results so far have been really encouraging, although the long-term outcome data are still being monitored. Ideally, continued progress in this field will provide more outcomes research and simplified techniques.

Finally, it is possible that ESD may be used for extended indications in the West. If this occurs, ESD may have a greater therapeutic impact than it does in Japan, because of the higher surgical mortality in the West.

\section{References}

1. Rembacken BJ, Gotoda T, Fujii T, Axon ATR. Endoscopic mucosal resection. Endoscopy 2001:33:709-18.

2. Soetikno R, Gotoda T, Nakanishi Y, Soehendra N. Endoscopic mucosal resection. Gastrointest Endosc 2003;57:567-79.

3. Hull MJ, Mino-Kenudson M, Nishioka NS, Ban S, Sepehr A, Puricelli W, et al. Endoscopic mucosal resection: an improved diagnostic procedure for early gastroesophageal epithelial neoplasms. Am J Surg Pathol 2006;30:114-8.

4. Ludwig K, Klautke G, Bernhard J, Weiner R. Minimally invasive and local treatment for mucosal early gastric cancer. Surg Endosc 2005;19:1362-6.

5. Kitamura T, Tanabe S, Koizumi W, Mitomi H, Saigenji K. Argon plasma coagulation for early gastric cancer: technique and outcome. Gastrointest Endosc 2006;63:48-54.

6. Nagano H, Ohyama S, Fukunaga T, Seto Y, Fujisaki J, Yamaguchi $\mathrm{T}$, et al. Indications for gastrectomy after incomplete EMR for early gastric cancer. Gastric Cancer 2005;8:149-54.

7. Yano H, Kimura Y, Iwazawa T, Monden T. Laparoscopic management for local recurrence of early gastric cancer after endoscopic mucosal resection. Surg Endosc 2005;19:981-5.

8. Japanese Gastric Cancer Association. Japanese classification of gastric carcinoma-2 ${ }^{\text {nd }}$ English edition. Gastric Cancer 1998;1: $10-24$

9. Itoh H, Oohata Y, Nakamura K, Nagata T, Mibu R, Nakayama F. Complete 10-year postgastrectomy follow-up of early gastric cancer. Am J Surg 1989;158:14-6.

10. Ohta H, Noguchi Y, Takagi K, Nishi M, Kajitani T, Kato Y. Early gastric carcinoma with special reference to macroscopic classification. Cancer 1987;60:1099-106.

11. Maruyama K, Okabayashi K, Kinoshita T. Progress in gastric cancer surgery in Japan and its limits of radicality. World J Surg 1987;11:418-25.

12. Yamazaki H, Oshima A, Murakami R, Endoh S, Urukata T. A long term follow-up study of patients with gastric cancer detected by mass screening. Cancer 1989;63:613-7.
13. Sano T, Sasako M, Kinoshita T, Maruyama K. Recurrence of early gastric cancer. Follow-up of 1475 patients and review of Japanese literature. Cancer 1993;72:3174-8.

14. Sasako M. Risk factors for surgical treatment in the Dutch gastric cancer trial. Br J Surg 1997;84:1567-71.

15. Bonenkamp JJ, Songun I, Hermans J, Sasako M, Welvaart K, Plukker JT, et al. Randomised comparison of morbidity after D1 and D2 dissection for gastric cancer in 996 Dutch patients. Lancet 1995;345:745-8.

16. Sasako M, Kinoshita T, Maruyama K. Prognosis of early gastric cancer. Stomach and Intestine (in Japanese; abstract in English) 1993;28:139-46.

17. Sano T, Kobori O, Muto T. Lymph node metastasis from early gastric cancer: endoscopic resection of tumour. Br J Surg 1992;79: $241-4$

18. Tsujitani S, Oka S, Saito H, Kondo A, Ikeguchi M, Maeta M, et al. Less invasive surgery for early gasric cancer based on the low probability of lymph node metastasis. Surgery 1999;125: $148-54$.

19. Yanai H, Matsubara Y, Kawano T, Okamoto T, Hirano A, Nakamura Y, et al. Clinical impact of strip biopsy for early gastric cancer. Gastrointest Endosc 2004;60:771-7.

20. Farrell JJ, Lauwers GY, Brugge WR. Endoscopic mucosal resection using a cap-fitted endoscope improves tissue resection and pathology interpretation: an animal study. Gastric Cancer 2006;9: 3-8.

21. Gotoda T, Sasako M, Ono H, Katai H, Sano T, Shimoda T. An evaluation of the necessity of gastrectomy with lymph node dissection for patients with submucosal invasive gastric cancer. Br J Surg 2001;88:444-9.

22. Etoh T, Katai H, Fukagawa T, Sano T, Oda I, Gotoda T, et al. Treatment of early gastric cancer in the elderly patient: results of EMR and gastrectomy at a national referral center in Japan. Gastrointest Endosc 2005;62:868-71.

23. Yanai H, Noguchi T, Mizumachi S, Tokiyama H, Nakamura H, Tada M, et al. A blind comparison of the effectiveness of endoscopic ultrasonography and endoscopy in staging early gastric cancer. Gut 1999;44:361-5.

24. Sano T, Okuyama Y, Kobori O, Shimizu T, Morioka Y. Early gastric cancer; endoscopic diagnosis of depth of invasion. Dig Dis Sci 1990;35:1340-35.

25. Saitoh Y, Obara T, Watari J, Nomura M, Taruishi M, Orii Y, et al. Invasion depth diagnosis of depressed type early colorectal cancers by combined use of videoendoscopy and chromoendoscopy. Gastrointest Endosc 1998;48:362-70.

26. Ohashi S, Segawa K, Okamura S, Mitake M, Urano H, Shimodaira $\mathrm{M}$, et al. The utility of endoscopic ultrasonography and endoscopy in the endoscopic mucosal resection of early gastric cancer. Gut 1999;45:599-604.

27. Akahoshi K, Chijiwa Y, Hamada S, Sasaki I, Nawata H, Kabemura $\mathrm{T}$, et al. Pretreatment staging of endoscopically early gastric cancer with a $15 \mathrm{MHz}$ ultrasound catheter probe. Gastrointest Endosc 1998;48:470-6.

28. Ahmad NA, Kochman ML, Long WB, Furth EE, Ginsberh GG. Efficacy, safety, and clinical outcomes of endoscopic mucosal resection: a study of 101 cases. Gastrointest Endosc 2002;55: $390-6$.

29. Katsube T, Konno S, Hamaguchi K, Shimakawa T, Naritaka Y, Ogawa $\mathrm{K}$, et al. The efficacy of endoscopic mucosal resection in the diagnosis and treatment of group III gastric lesions. Anticancer Res 2005;25:3513-6.

30. Yamao T, Shirao K, Ono H, Kondo H, Saito D, Yamaguchi H, et al. Risk factors for lymph node metastasis from intramucosal gastric carcinoma. Cancer 1996;77:602-6.

31. Tsujitani S, Oka S, Saito H, Kondo A, Ikeguchi M, Maeta M, et al. Less invasive surgery for early gastric cancer based on the low probability of lymph node metastasis. Surgery 1999;125:148-54.

32. Japanese Gastric Cancer Association. Gastric cancer treatment guideline (in Japanese). 2nd ed. Kanehara-Shuppan, Tokyo, 2004. 
33. Hiki Y. Endoscopic mucosal resection (EMR) for early gastric cancer. (in Japanese with English abstract). Jpn J Surg 1996;97: 273-8.

34. Ohgami M, Otani Y, Kumai K, Kubota T, Kitajima M. Laparoscopic surgery for early gastric cancer (in Japanese with English abstract). Jpn J Surg 1996;97:279-85.

35. Yasuda K, Shiraishi N, Suematsu T, Yamaguchi K, Adachi Y, Kitano S. Rate of detection of lymph node metastasis is correlated with the depth of submucosal invasion in early stage gastric carcinoma. Cancer 1999;85:2119-23.

36. Oizumi H, Matsuda T, Fukase K, Furukawa A, Mito S, Takahashi K. Endoscopic resection for early gastric cancer: the actual procedure and clinical evaluation (in Japanese with English abstract). Stomach and Intestine 1991;26:289-300.

37. Fujii K, Okajima K, Isozaki H, Hara H, Nomura E, Sako S, et al. A clinicopathological study on the indications of limited surgery for submucosal gastric cancer (in Japanese with English abstract). Jpn J Gastroenterol Surg 1998;31:2055-62.

38. Gotoda T, Yanagisawa A, Sasako M, Ono H, Nakanishi Y, Shimoda T, et al. Incidence of lymph node metastasis from early gastric cancer: estimation with a large number of cases at two large centers. Gastric Cancer 2000;3:219-25.

39. Soetikno R, Kaltenbach T, Yeh R, Gotoda T. Endoscopic mucosal resection for early cancers of the upper gastrointestinal tract. J Clin Oncol 2005;23:4490-8.

40. Deyhle P, Largiader F, Jenny S, Fumagalli I. A method for endoscopic electroresection of sessile colonic polyps. Endoscopy 1973; 5:38-40.

41. Tada M, Shimada M, Murakami F, Mizumachi M, Arima K, Yanai H, et al. Development of strip-off biopsy (in Japanese with English abstract). Gastroenterol Endosc 1984;26:833-9.

42. Hirao M, Masuda K, Ananuma T, Nala H, Noda K, Matsuura K, et al. Endoscopic resection of early gastric cancer and other tumors with local injection of hypertonic saline-epinephrine. Gastrointest Endosc 1988;34:264-9.

43. Inoue H, Takeshita K, Hori H, Muraoka Y, Yoneshima H, Endo M. Endoscopic mucosal resection with a cap-fitted panendoscope for esophagus, stomach, and colon mucosal lesions. Gastrointest Endosc 1993;39:58-62.

44. Matsuzaki K, Nagao S, Kawaguchi A, Miyazaki J, Yoshida Y, Kitagawa Y, et al. Newly designed soft prelooped cap for endoscopic mucosal resection of gastric lesions. Gastrointest Endosc 2003;57:242-6.

45. Kume K, Yamasaki M, Kubo K, Mitsuoka H, Ota T, Matsuhashi T, et al. EMR of upper GI lesions when using a novel soft, irrigation, prelooped hood. Gastrointest Endosc 2004;60:124-8.

46. Akiyama M, Ota M, Nakajima H, Yamagata K, Munakata A. Endoscopic mucosal resection of gastric neoplasms using a ligating device. Gastrointest Endosc 1997;45:182-6.

47. Korenaga D, Haraguchi M, Tsujitani S, Okamura T, Tamada R, Sugimachi K. Clinicopathological features of mucosal carcinoma of the stomach with lymph node metastasis in 11 patients. Br J Surg 1986;73:431-3.

48. Ell C, May A, Gossner L, Pech O, Gunter E, Mayer G, et al. Endoscopic mucosectomy of early cancer and high-grade dysplasia in Barrett's esophagus. Gastroenterol 2000;118:670-7.

49. Tanabe S, Koizumi W, Mitomi H, Nakai H, Murakami S, Nagaba $\mathrm{S}$, et al. Clinical outcome of endoscopic aspiration mucosectomy for early stage gastric cancer. Gastrointest Endosc 2002;56: 708-13.

50. Eguchi T, Gotoda T, Oda I, Hamanaka H, Hasuike N, Saito D. Is endoscopic one-piece mucosal resection essential for early gastric cancer? Dig Endosc 2003;15:113-6.

51. Ono H, Kondo H, Gotoda T, Shirao K, Yamaguchi H, Saito D, et al. Endoscopic mucosal resection for treatment of early gastric cancer. Gut 2001;48:225-9.

52. Hosokawa K, Yoshida S. Recent advances in endoscopic mucosal resection for early gastric cancer (in Japanese with English abstract). Jpn J Cancer Chemother 1998;25:483.
53. Gotoda T, Kondo H, Ono H, Saito Y, Yamaguchi H, Saito D, et al. A new endoscopic mucosal resection (EMR) procedure using an insulation-tipped diathermic (IT) knife for rectal flat lesions. Gastrointest Endosc 1999;50:560-3.

54. Gotoda T. A large endoscopic resection by endoscopic submucosal dissection (ESD) procedure. Clin Gastroenterol Hepatol 2005; 3:S71-3.

55. Oyama T, Kikuchi Y. Aggressive endoscopic mucosal resection in the upper GI tract - Hook knife EMR method. Min Invas Ther Allied Technol 2002;11:291-5.

56. Yahagi N, Fujishiro M, Kakushima N, Kobayashi K, Hashimoto T, Oka M, et al. Endoscopic submucosal dissection for early gastric cancer using the tip of an electrosurgical snare (thin type). Dig Endosc 2004;16:34-8.

57. Yamamoto H, Kawata H, Sunada K, Sasaki A, Nakazawa K, Miyata T, et al. Successful en bloc resection of large superficial tumors in the stomach and colon using sodium hyaluronate and small-caliber-tip transparent hood. Endoscopy 2003;35:690-4.

58. Rosch T, Sarbia M, Schmacher B, Deinert K, Frimberger E, Toermer $\mathrm{T}$, et al. Attempted endoscopic en bloc resection of mucosal and submucosal tumors using insulated-tip knives: a pilot series. Endoscopy 2004;36:788-801.

59. Choi IJ, Kim CG, Chang HJ, Kim SG, Kook MC, Bae JM. The learning curve for EMR with circumferential mucosal incision in treating intramucosal gastric cancer. Gastrointest Endosc 2005; 62:860-5.

60. Gotoda T, Friedland S, Hamanaka H, Soetikno R. A learning curve for advanced endoscopic resection. Gastrointest Endosc 2005;62:866-7.

61. Kaneko E, Hanada H, Kasugai T, Ogoshi K, Niwa K. The survey of gastrointestinal endoscopic complications in Japan (in Japanese). Gastroenterol Endosc 2000;42:308-13.

62. Lee SY, Kim JJ, Lee JH, Kim YH, Rhee PL, Paik SW, et al. Healing rate of EMR-induced ulcer in relation to the duration of treatment with omeprazole. Gastrointest Endosc 2004;60:213-7.

63. Tada M. One piece resection and piecemeal resection of early gastric cancer by strip biopsy (in Japanese with English abstract). Tokyo: Igaku-Shoin; 1998; p. 68-87.

64. Oda I, Gotoda T, Hamanaka H, Eguchi T, Saito Y, Matsuda T, et al. Endoscopic submucosal dissection for early gastric cancer: Technical feasibility, operation time and complications from a large series of consecutive cases. Dig Endosc 2005;17:54-8.

65. Fujishiro M, Ono H, Gotoda T, Yamaguchi H, Kondo H, Saito D. Usefulness of Maalox for detection of the precise bleeding points and confirmation of hemostasis on gastrointestinal hemorrhage. Endoscopy 2000;32:196.

66. Okano A, Hajiro K, Takakuwa H, Nishio A, Matsushita M. Predictors of bleeding after endoscopic mucosal resection of gastric tumors. Gastrointest Endosc 2003;57:687-90.

67. Shiba M, Higuchi K, Kadouchi K, Montani A, Yamamori K, Okazaki H, et al. Risk factors for bleeding after endoscopic mucosal resection. World J Gastroenterol 2005;14:7335-9.

68. Tsunada S, Ogata S, Ohyama T, Ootani H, Oda K, Kikkawa A, et al. Endoscopic closure of perforations caused by EMR in the stomach by application of metallic clips. Gastrointest Endosc 2003;57:948-51.

69. Minami S, Gotoda T, Ono H, Oda I, Hamanaka H. Complete endoscopic closure using endoclips for gastric perforation during endoscopic resection for early gastric cancer can avoid emergent surgery. Gastrointest Endosc 2006;63:596-601.

70. Yamamoto H, Kawata H, Sunada K, Satoh K, Kaneko Y, Ido K, et al. Success rate of curative endoscopic mucosal resection with circumferential mucosal incision assisted by submucosal injection of sodium hyaluronate. Gastrointest Endosc 2002;56:507-13.

71. Fujishiro M, Yahagi N, Nakamura M, Kakushima N, Kodashima S, Ono S, et al. Successful outcomes of a novel endoscopic teratment for GI tumors: endoscopic submucosal dissection with a mixture of high-molecular-weight hyaluronic acid, glycerin, and sugar. Gastrointest Endosc 2006;63:243-9. 
72. Fujishiro M, Yahagi N, Kashimura K, Matsuura T, Nakamura M, Kakushima N, et al. Tissue damage of different submucosal injection solutions for EMR. Gastrointest Endosc 2005;62:933-42.

73. Schlemper RJ, Itabashi M, Kato Y, Lewin KJ, Riddell RH, Shimoda T, et al. Differences in diagnostic criteria for gastric carcinoma between Japanese and Western pathologists. Lancet 1997;349:1725-9.

74. Schlemper RJ, Riddell RH, Kato Y, Borchard F, Cooper HS, Dawsey SM, et al. The Vienna classification of gastrointestinal epithelial neoplasia. Gut 2000;47:251-5.

75. Nunobe S, Gotoda T, Oda I, Katai H, Sano T, Shimoda T, et al. Distribution of the deepest penetrating point of minute submucosal gastric cancer. Jpn J Clin Oncol 2005;35:587-90.

76. Takekoshi T, Baba Y, Ota H, Kato Y, Yanagisawa A, Takagi K, et al. Endoscopic resection of early gastric carcinoma: results of a retrospective analysis of 308 cases. Endoscopy 1994;26:352-8.

77. Kojima T, Parra-Blanco A, Takahashi H, Fujita R. Outcome of endoscopic mucosal resection for early gastric cancer: review of the Japanese literature. Gastrointest Endosc 1998;48:550-4.

78. Conio M, Ponchon T, Blanchi S, Filibertiet R. Endoscopic mucosal resection. Am J Gastroenterol 2006;101:653-63.

79. Nasu J, Doi T, Endo H, Nishina T, Hirasaki S, Hyodo I. Characteristics of metachronous multiple early gastric cancers after endoscopic mucosal resection. Endoscopy 2005;37:990-3.
80. Nakajima T, Oda I, Gotoda T, Hamanaka H, Eguchi T, Yokoi C, et al. Metachronous gastric cancers after endoscopic resection: how effective is annual endoscopic surveillance? Gastric Cancer 2006;9:93-8.

81. Isshi K, Tajiri H, Fujisaki J, Mochizuki K, Matsuda K, Nakamura $\mathrm{Y}$, et al. The effectiveness of a new multibending scope for endoscopic mucosal resection. Endoscopy 2004;36:294-7.

82. Kondo H, Gotoda T, Ono H, Oda I, Kozu T, Fijishiro M, et al. Percutaneous traction-assisted EMR by using an insulationtipped electrosurgical knife for early stage gastric cancer. Gastrointest Endosc 2004;59:284-8.

83. Kobayashi T, Gotoda T, Tamakawa K, Ueda H, Kakizoe T. Magnetic anchor for more effective endoscopic mucosal resection. Jpn J Clin Oncol 2004;34:118-23.

84. Abe N, Mori T, Izumisato Y, Sasaki H, Ueki H, Masaki T, et al. Successful treatment of an undifferentiated early gastric cancer by combined en bloc EMR and laparoscopic regional lymphadenectomy. Gastrointest Endosc 2003;57:972-5.

85. Abe N, Mori T, Takeuchi H, Yoshida T, Ohki A, Ueki H, et al. Laparoscopic lymph node dissection after endoscopic submucosal dissection: a novel and minimally invasive approach to treating early-stage gastric cancer. Am J Surg 2005;190:496-503. 